\title{
Comparative clinical efficacy of anatomic plate and Kirschner wire internal fixation in midshaft clavicle fractures: A meta-analysis
}

\author{
DAIHONG YANG ${ }^{1}$, JIAWEI ZHOU ${ }^{2}$ and LIJUN WANG ${ }^{1}$ \\ ${ }^{1}$ Department of Orthopedics, Chongqing Dazu District People's Hospital, Chongqing 4023601; \\ ${ }^{2}$ Department of Orthopedics, People's Hospital of Wuhan University, Wuhan, Hubei 430061, P.R. China
}

Received September 2, 2021; Accepted November 1, 2021

DOI: $10.3892 / \mathrm{mi} .2021 .21$

\begin{abstract}
Midshaft (mid)-clavicle fractures are the most common type of clavicle fractures. The Kirschner wire (KW) and anatomic plate (AP) are two commonly used surgical treatment methods for mid-clavicle fractures, of which the use of an AP appears to be a more effective option. The present study performed a meta-analysis of a number of published studies on the treatment of mid-clavicle fractures with APs and KWs, in order to compare the advantages and disadvantages of the two treatments, so as to select a more effective treatment approach. The articles were obtained from several databases, including Cochrane Library, PubMed, Embase, CNKI, Wanfang, VIP and Chinese Biomedical Literature Database. The search period was from database establishment to June, 2021. Research was obtained by two authors who individually searched the aforementioned databases. For controversial studies, decisions were made by two authors (JZ and LW). A total of 20 studies involving 1,739 patients were included in the meta-analysis, including eight randomized controlled studies and 12 cohort trials. The results of the meta-analysis suggested that: Compared with the KW group, the AP group exhibited significant differences in incision length [standardized mean difference $(\mathrm{SMD})=2.40 ; 95 \%$ confidence interval $(\mathrm{CI})$, 1.93-2.86], constant function score (6 months; $\mathrm{SMD}=1.59$; 95\% CI, 1.29-1.89) and fracture healing time (SMD=-1.48; 95\% CI, -2.09 to -0.87$)(\mathrm{P}<0.05)$. However, no significant differences were observed in the duration of the surgery $(\mathrm{SMD}=1.19 ; 95 \% \mathrm{CI},-0.19-2.57)$ and intraoperative blood loss $(\mathrm{SMD}=0.10 ; 95 \% \mathrm{CI},-3.13-3.32)(\mathrm{P}>0.05)$. Compared with the KW group, significant differences were observed in post-operative efficacy (OR, 4.81; 95\% CI, 3.10-7.46) and the
\end{abstract}

Correspondence to: Dr Jiawei Zhou, Department of Orthopedics, People's Hospital of Wuhan University, 238 Jiefang Road (formerly 99 Zhangzhidong Road), Wuchang, Wuhan, Hubei 430061, P.R. China

E-mail: 18636119217@163.com

Key words: bone, fracture, clavicle fracture, midshaft clavicle fracture, anatomic plate, Kirschner wire, fixation incidence of post-operative complications (OR, 0.16; 95\% CI, $0.05-0.55)$ in the AP group $(\mathrm{P}<0.05)$. On the whole, the AP and $\mathrm{KW}$ are two common materials for the clinical surgical treatment of mid-clavicle fractures. The present study confirmed that there was no significant difference between the two treatments as regards the duration of surgery and intraoperative blood loss; however, for post-operative shoulder joint function recovery, fracture healing state and healing time, the AP was significantly more effective than the KW. The post-operative complication rate of the AP group was significantly lower than that of the KW group. However, further prospective, large-sample randomized controlled studies are required to provide more concrete evidence for verification.

\section{Introduction}

Clavicle fractures are a common type of fracture observed in clinical practice, accounting for $2.6-10 \%$ of total body fractures; $80 \%$ of clavicle fractures occur in the midshaft clavicle, while distal and proximal clavicle fractures have a low incidence $(1,2)$. Previous studies have reported that the incidence of mid-clavicle fractures is 29-64 cases per 100,000 individuals each year; in addition, the incidence of such fractures in children is significantly higher than that in adults $(3,4)$. The traditional non-operative treatment used is usually a sling or figure-of-eight bandage, even if the clavicle fracture is displaced (5). If patients with a clavicle fracture are not treated in a timely and effective manner, their limb function and quality of life is severely affected. It has been reported that the rate of bone non-union following the conservative treatment of comminuted fractures can amount to $15 \%$ (6). Compared with conservative (non-surgical) treatments, early surgical treatment can significantly improve the prognosis of fractures and can reduce the incidence of non-unions and malunions (7). Traditional surgical treatment with Kirschner wire (KW) fixation is more common; however, the associated risk of fracture end displacement and malunion is prohibitive, and for patients with comminuted or severely unstable clavicle fractures, it is difficult to achieve satisfactory results with traditional treatments (8). It has been reported that $>50 \%$ of clinical clavicle fractures are displaced, and the risk of fracture malunion and discontinuity is relatively high; in addition, improper treatment can lead to the development of severe complications (9). 
With the continuous exploration and development of treatment methods and the continuous improvement of patient requirements, the treatment of clavicle fractures with an anatomic plate (AP) has been widely used in clinical practice. At present, AP and KW fixation are widely used in clinical practice for the treatment of clavicle fractures. $\mathrm{KW}$ wire fixation requires a smaller incision, and less soft tissue and periosteum dissection; however, it is associated with a high possibility of fracture displacement and re-operation. Although AP requires a long surgical incision, it has a good stability, fewer complications and a higher post-operative fracture healing rate, particularly for comminuted and severely unstable fractures. Despite the fact that a variety of fixation methods have been described in the published literature to date, the optimal treatment of mid-clavicle fractures remains controversial $(10,11)$. However, to date, the available evidence is not sufficient to confirm the advantages and disadvantages for the use of the $\mathrm{AP}$ and KW in mid-clavicle fractures. Therefore, the present study aimed to further explore the treatment of mid-clavicle fractures by analyzing available clinical studies on the treatment of such fractures with an AP and KW, in order to select a more suitable clinical treatment method.

\section{Data and methods}

Literature search and inclusion criteria. The inclusion criteria were as follows: Randomized controlled studies or cohort trials on mid-clavicle fractures, the exclusion of pathological fractures, the inclusion of at least one evaluation index and the inclusion of a full text. The exclusion criteria were the following: No mid-clavicle fractures, multiple injuries, no mean values. For contradictory articles and data, any issues were resolved by the corresponding author (JZ). Two researchers (DY and LW) searched the database and randomly searched the literature on AP and KW fixation for mid-clavicle fractures. The databases used included the Cochrane Library (https://www. cochrane.org), PubMed (https://www.ncbi.nlm.nih.gov/), Embase (https://www.embase.com), CNKI (http://www.cnki. net/),Wanfang (http://www.wanfangdata.com.cn/index.html), VIP (http://www.cqvip.com/) and CBM (sinomed.ac.cn). The retrieval time used was from the establishment of the database to June, 2021. The key words used for the search were the following: Clavicle fracture, anatomical plate and Kirschner wire, and finally, the articles included at least one evaluation index to evaluate the effectiveness of the treatment for mid-clavicular fractures. They included mean incision length, mean surgical duration, blood loss, constant function score (6 months), fracture healing time, post-operative efficacy and complication rate. The retrieval strategies for PubMed and CBM are presented in Fig. 1 (each \# symbol and number in the figure represent a retrieval step).

Data extraction and quality evaluation. The basic features of the included studies, including the number of cases in the AP and KW groups, mean age, fracture type, duration of follow-up, and randomized controlled studies or cohort trials, were obtained by two researchers (DY and LW) by reading the title, abstract, key words and finally, the full article. RevMan 5.0 software Cochrane bias risk assessment (https://training. cochrane.org/handbook) was used for randomized controlled studies and the Newcastle-Ottawa Scale (NOS) was used for cohort trials, in order to evaluate the quality. The scale total score is nine points, and a score of $\geq 6$ is considered high-quality research (12).

Statistical analysis. For continuous data obtained, the standardized mean difference (SMD) and 95\% confidence intervals (CIs) were used to estimate validity. For dichotomous data, the odds ratios (ORs) were calculated. A meta-analysis was carried out using RevMan 5.0 software and the $I^{2}$ index for the heterogeneity of the studies. When the $I^{2}$ was $>50 \%$, indicating a high heterogeneity $(13,14)$, the random effects model was used for data analysis. When the $I^{2} \leq 50 \%$, the fixed effects model was used for data analysis. A value of $\mathrm{P}<0.05$ was considered to indicate a statistically significant difference.

\section{Results}

Features of the included articles. The Cochrane Library, PubMed, Embase, CNKI, Wanfang, VIP and CBM databases were searched. A total of 734 studies were retrieved, and 156 duplicate studies were found. After reading the titles and abstracts, 516 articles were excluded, including: 439 unrelated articles, 25 review articles, 23 conference articles and 29 case reports; remaining 62 articles. After reading the full articles, 41 articles were found to include no mid-clavicle fractures, and one article had no mean values. Finally, 20 articles containing at least one research index were obtained. Among these 20 articles, 17 included dichotomous variables and 8 included continuous variables. A flow chart of the included studies is presented in Fig. 2. In total, eight randomized controlled studies $(8,15-21)$ and 12 cohort trials $(22-33)$ were included. The basic characteristics of the studies are listed in Table I.

Qualitative evaluation and bias risk assessment of the included studies. There were 20 studies, including eight randomized controlled studies $(8,15-21)$ and 12 cohort trials (22-33). Participants were treated for mid-clavicular fractures within a certain period of time, and not all studies provided criteria for inclusion. The evaluation criteria for a post-operative good rate were not consistent. All the studies covered mid-clavicle fractures and provided specific surgical procedures. For the included studies, it was not suggested that all treatments were treated using the blind method, and the sample size of each study was not arranged in advance, and the end point of evaluation of the post-operative rehabilitation status of the patients was also randomly determined. The bias risk assessment of the included randomized controlled studies is illustrated in Fig. 3, and the quality assessment of the cohort studies is presented in Table II.

Average incision length. Of the 20 studies included, there were three studies $(8,22,25)$ that included the average incision length, as shown in Fig. 4. The results revealed that the incision length of the AP group was higher than that of the KW group $(\mathrm{SMD}=2.40 ; 95 \% \mathrm{CI}, 1.93-2.86 ; \mathrm{P}<0.00001)$.

Average duration of surgery. Of all the studies that were subjected to the meta-analysis, there were seven studies $(8,18,19,22,24,25,28)$ that demonstrated the results of 


\begin{tabular}{|c|c|c|}
\hline & \multirow{8}{*}{$\begin{array}{l}\text { CBM } \\
\# 1 \text { Clavicle fracture common } \\
\text { files: intelligence } \\
\text { \#2 Anatomic plate common } \\
\text { files: intelligence } \\
\# 5 \text { Kirschner wire common } \\
\text { files: intelligence } \\
\# 4 \text { \#1 and \#2 and \#3 }\end{array}$} \\
\hline \multicolumn{2}{|l|}{$\begin{array}{l}\text { PubMed } \\
\# 1 \text { Clavicle }\end{array}$} & \\
\hline \multicolumn{2}{|r|}{ \#20 Torsion fractures } & \\
\hline \multicolumn{2}{|l|}{ \#3 Collar bone } & \\
\hline \multicolumn{2}{|l|}{ \#4 Bone, collar } & \\
\hline \multicolumn{2}{|r|}{ \#23 Torsion fracture } & \\
\hline \multirow{3}{*}{$\begin{array}{l}\# 6 \text { Collar bones } \\
\# 7 \# 1 \text { or \#2 or \#3 or \#4 } \\
\text { or \#5 or \#6 }\end{array}$} & $\# 24 \# 8$ or \#9 or \#10 or \#11 or & \\
\hline & $\# 12$ or $\# 13$ or $\# 14$ or $\# 15$ or \#16 & \\
\hline & or \#17 or \#18 or \#19 or \#20 or & \\
\hline \multirow{2}{*}{$\begin{array}{l}\text { \#8 Fractures, bone } \\
\text { \#9 Broken bones }\end{array}$} & $\# 21$ or \#22 or \#23 & \\
\hline & \#25 Anatomic plates & \\
\hline \multirow{2}{*}{$\begin{array}{l}\text { \#10 Bone, broken } \\
\text { \#11 Bones, broken }\end{array}$} & \#26 Anatomic plates & \\
\hline & \#27 Anatomic plates & \\
\hline \multirow{2}{*}{$\begin{array}{l}\text { \#12 Broken bone } \\
\text { \#13 Bone fractures }\end{array}$} & \#28 \#25 or \#26 or \#27 & \\
\hline & \#29 Kirschner pin & \\
\hline \multirow{5}{*}{$\begin{array}{l}\text { \#14 Bone fracture } \\
\text { \#15 Fracture, bone } \\
\text { \#16 Spiral fractures } \\
\text { \#17 Fracture, spiral } \\
\text { \#18 Fractures, spiral }\end{array}$} & \#30 Kirschner pins & \\
\hline & \#31 Kirschner wires & \\
\hline & \#32 Kirschner wires & \\
\hline & $\# 33$ \#29 or \#30 or \#31 or \#32 & \\
\hline & $\begin{array}{l}\# 34 \text { \#7 and \#24 and \#28 and } \\
\# 33\end{array}$ & \\
\hline
\end{tabular}

Figure 1. PubMed and CBM search strategy. CBM, Chinese Biomedical Literature Database. Each \# symbol and number in the figure represent a retrieval step.

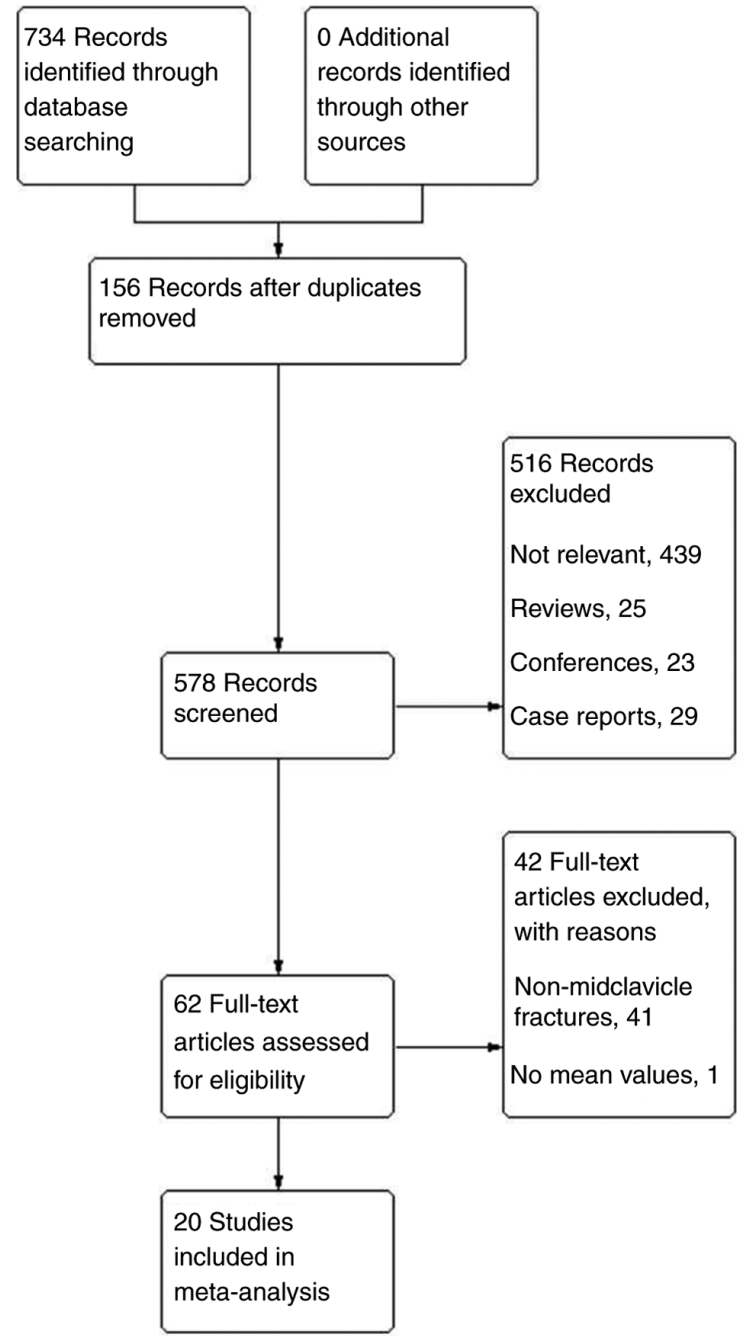

Figure 2. Flow chart of the included studies.

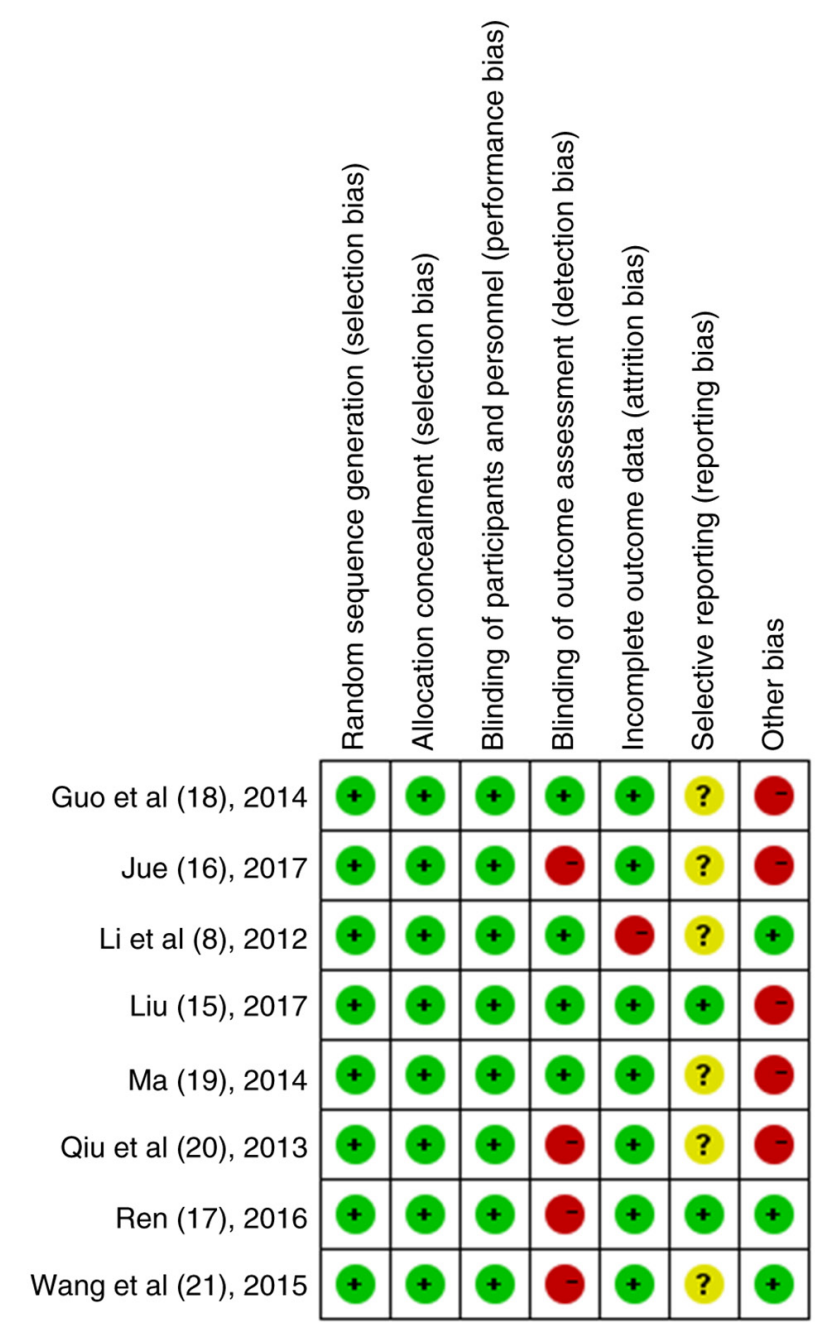

Figure 3. Quality evaluation of the randomized controlled studies, all of which were grade $\mathrm{B}$ or above. 


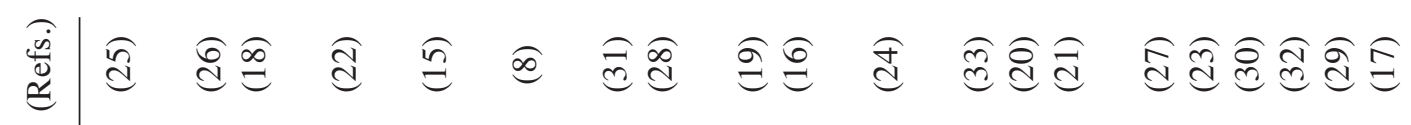

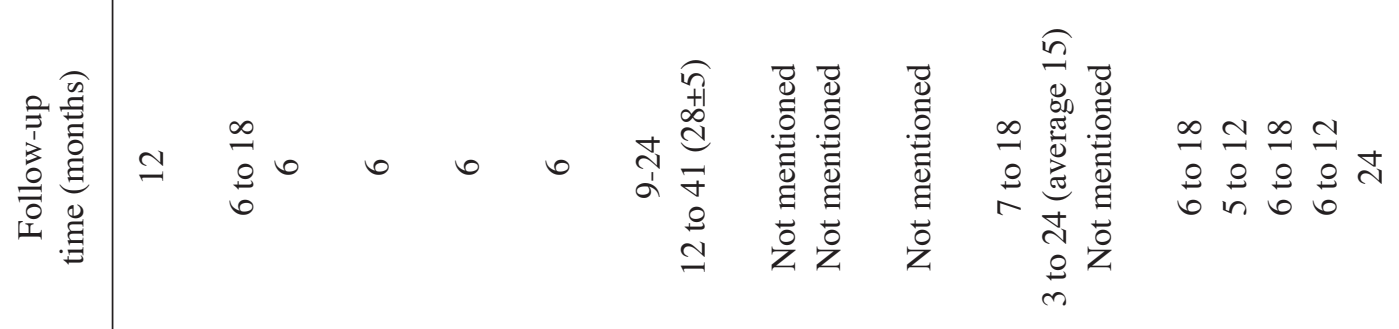

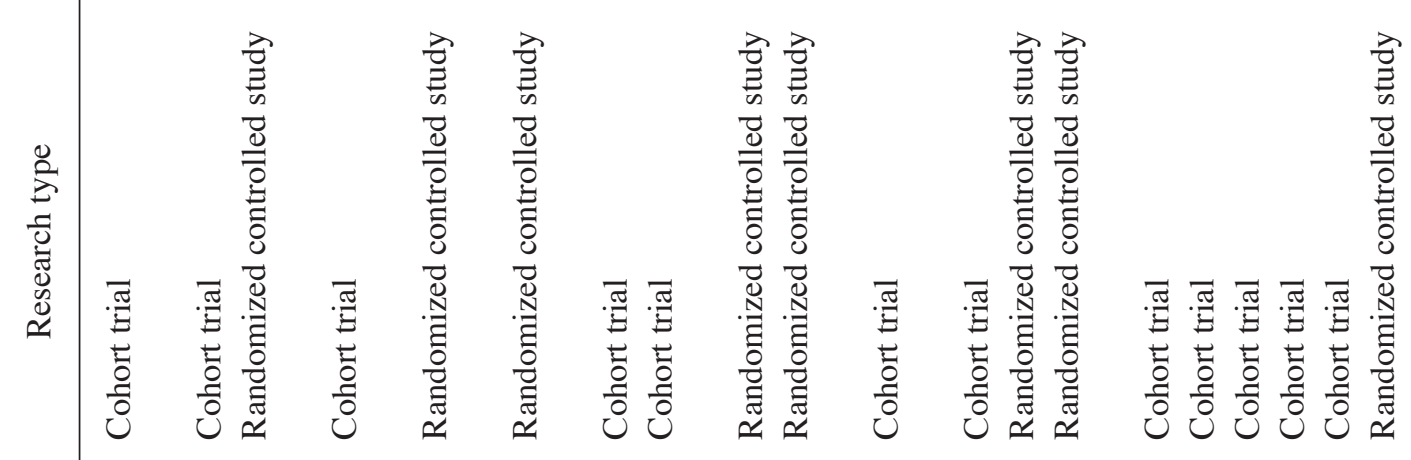

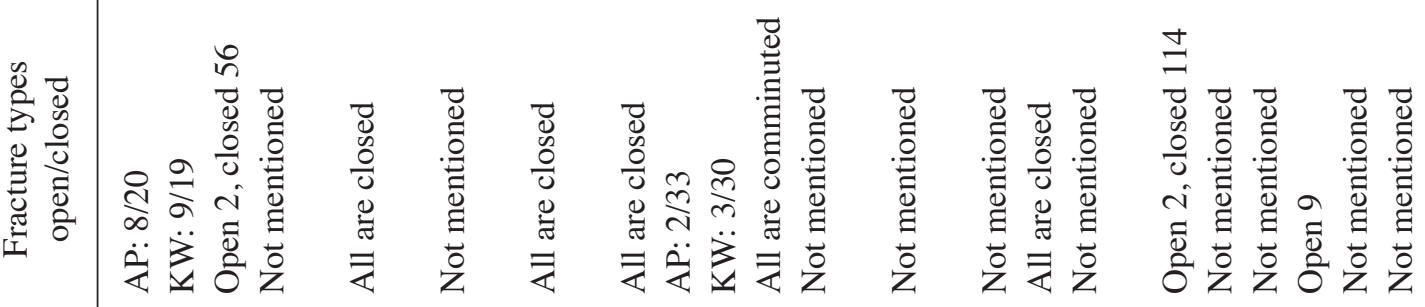

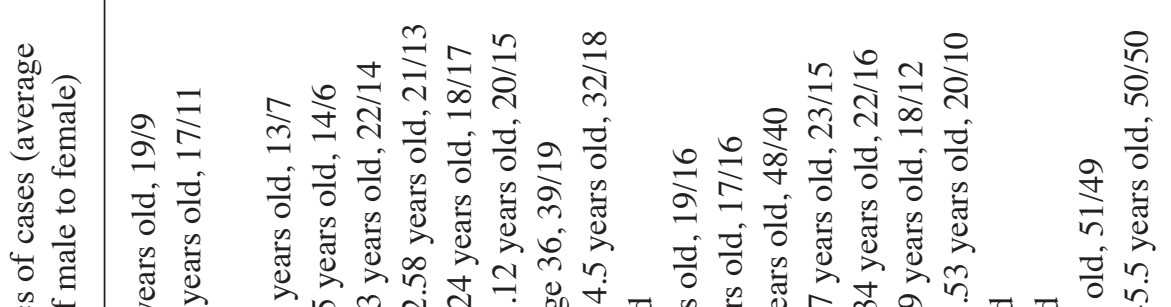

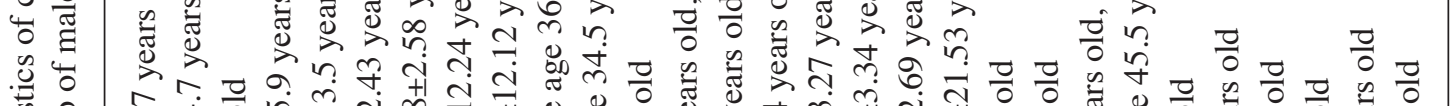

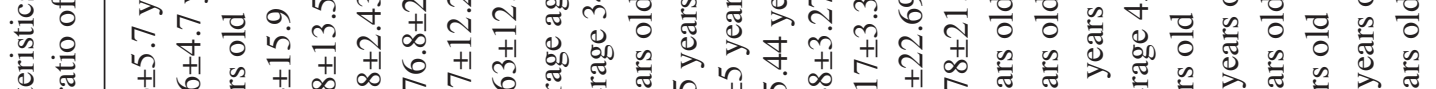

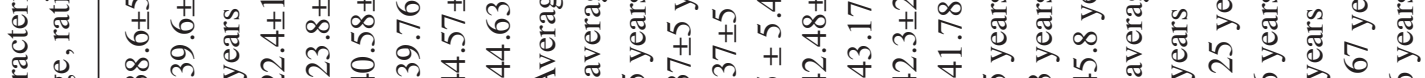
范

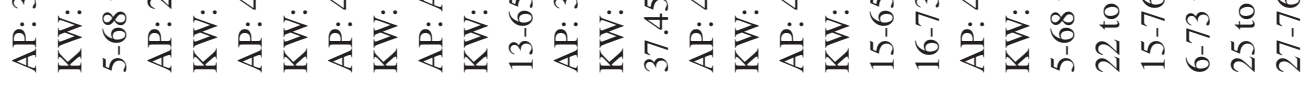

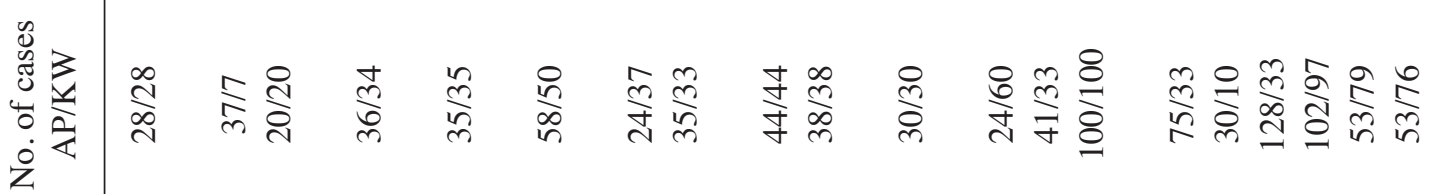

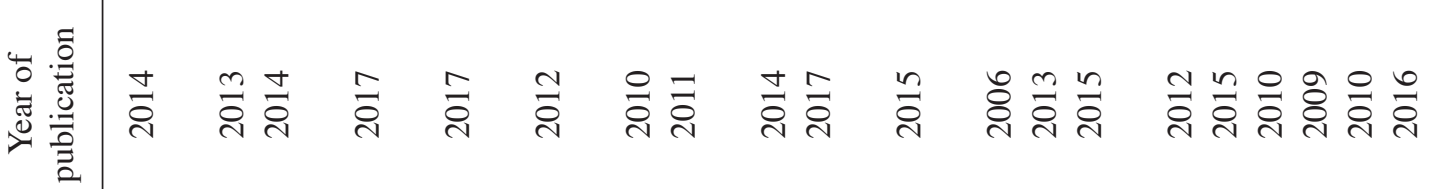

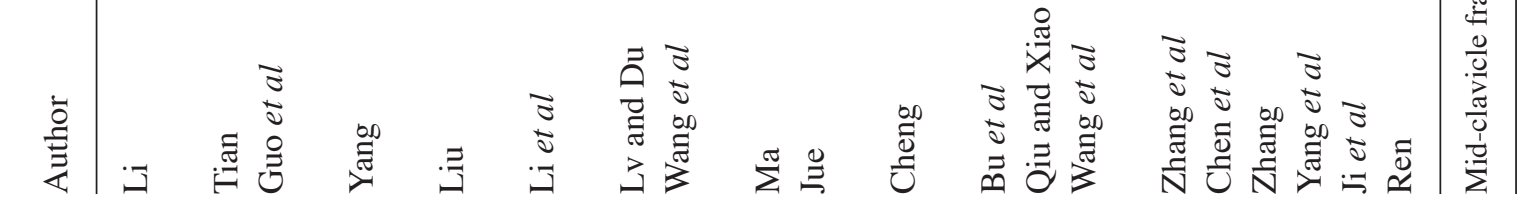


Table II. Quality evaluation of the cohort studies, all of which were $>6$ points.

\begin{tabular}{|c|c|c|c|c|c|c|c|c|c|c|}
\hline \multirow[b]{2}{*}{ Author/(Refs.) } & \multirow[b]{2}{*}{ Year of publication } & \multicolumn{4}{|c|}{ Case selection } & \multirow[b]{2}{*}{ Comparability } & \multicolumn{3}{|c|}{$\begin{array}{l}\text { Outcome } \\
\text { measure }\end{array}$} & \multirow[b]{2}{*}{ Score } \\
\hline & & 1 & 2 & 3 & 4 & & A & B & $\mathrm{C}$ & \\
\hline $\mathrm{Li}(25)$ & 2014 & $*$ & $*$ & $*$ & $*$ & $* *$ & & $*$ & $*$ & 8 \\
\hline Tian (26) & 2013 & & $*$ & $*$ & $*$ & $*$ & & $*$ & $*$ & 6 \\
\hline Yang (22) & 2017 & $*$ & $*$ & $*$ & $*$ & $* *$ & & $*$ & & 7 \\
\hline $\mathrm{Lu}$ and $\mathrm{Du}(31)$ & 2010 & & * & * & $*$ & $*$ & & * & $*$ & 6 \\
\hline Wang et al (28) & 2011 & $*$ & $*$ & $*$ & $*$ & $* *$ & & $*$ & & 7 \\
\hline Cheng (24) & 2015 & $*$ & $*$ & $*$ & $*$ & $* *$ & $*$ & & & 7 \\
\hline Bu et al (33) & 2006 & $*$ & $*$ & $*$ & $*$ & $* *$ & & $*$ & & 7 \\
\hline Zhang et al (27) & 2012 & & $*$ & $*$ & $*$ & $*$ & & $*$ & $*$ & 6 \\
\hline Chen et al (23) & 2015 & $*$ & $*$ & $*$ & $*$ & $*$ & $*$ & $*$ & $*$ & 8 \\
\hline Zhang (30) & 2010 & $*$ & $*$ & $*$ & $*$ & $*$ & & $*$ & & 6 \\
\hline Yang et al (32) & 2009 & & $*$ & $*$ & $*$ & $*$ & $*$ & $*$ & $*$ & 7 \\
\hline Ji et al (29) & 2010 & $*$ & $*$ & $*$ & $*$ & $*$ & & $*$ & & 6 \\
\hline
\end{tabular}

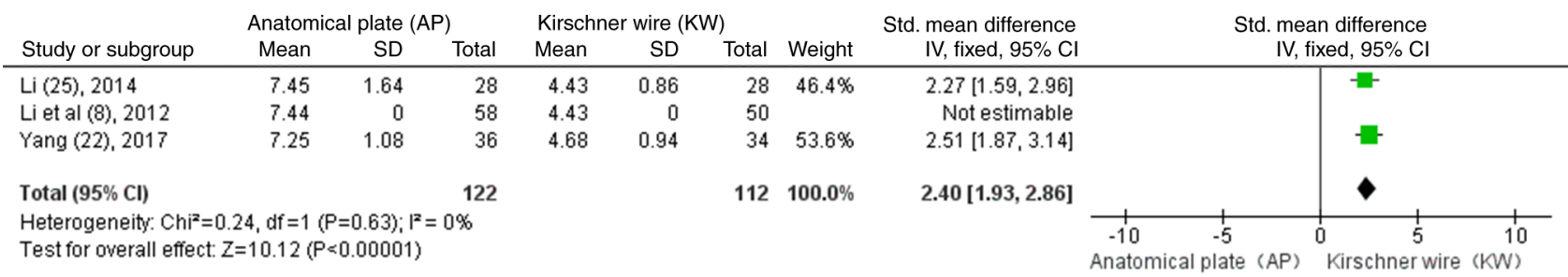

Figure 4. Comparison of the average incision length between the AP and KW group in the treatment of mid-clavicle fractures. The diamond shapes represent the results of statistical analysis. The squares represent the weight of each study, and the horizontal lines represent the $95 \%$ confidence intervals for each study. The results revealed that the incision length of the KW group was comparatively shorter than that of the AP group. AP, anatomic plate; KW, Kirschner wire.

duration of surgery, as shown in Fig. 5. The results revealed that there were no significant differences $(\mathrm{P}>0.05)$ in the duration of surgery between the AP and $\mathrm{KW}$ group in the treatment of mid-clavicle fractures $(\mathrm{SMD}=1.19 ; 95 \% \mathrm{CI},-0.19-2.57$; $\mathrm{P}=0.09$ ).

Bleeding/blood loss. At the time of the meta-analysis, there were four studies $(18,22,24,28)$ that included the findings of any bleeding associated with the treatments, as shown in Fig. 6. The results revealed that there were no significant differences $(\mathrm{P}>0.05)$ in blood loss between the AP and $\mathrm{KW}$ group in the treatment of mid-clavicle fractures $(\mathrm{SMD}=0.10$; 95\% CI, -3.13-3.32; $\mathrm{P}=0.95)$.

Constant function score (6 months). There were three studies found for the comparison of the constant function scores $(8,22,25)$, as shown in Fig. 7 . The SMD from the three studies was 1.59 (95\% CI, 1.29-1.89; P<0.00001). These results revealed that compared with the $\mathrm{KW}$ group, the AP group had a better recovery of function following surgery $(\mathrm{P}<0.05)$.

Fracture healing time (weeks). There were five studies available for the comparison of the fracture healing time $(16,19,22,24,28)$, as shown in Fig. 8. The SMD obtained from the analysis of the data from these five studies was -1.48 (95\% CI, -2.09 to -0.87 ; $\mathrm{P}<0.00001$ ). These results revealed that the AP group had a shorter fracture healing time than the KW group $(\mathrm{P}<0.05)$.

Post-operative efficacy assessment. There were nine studies available for the assessment of the post-operative efficacy of the two surgical methods $(16,17,20,21,24,28,29,31,33)$, as shown in Fig. 9. The results revealed that compared with the KW group, the AP group had a better post-operative recovery rate $(\mathrm{OR}, 4.81 ; 95 \% \mathrm{CI}, 3.10-7.46$; $\mathrm{P}<0.00001$; $\mathrm{P}<0.05)$.

Complications. There were 12 studies available on the incidence of post-operative complications between the two surgical methods $(8,17-19,22,23,26-28,30-32)$, as shown in Fig. 10. The results revealed that compared with the KW group, the AP group had a relatively lower incidence of post-operative complications (OR 0.16; 95\% CI, 0.05-0.55; $\mathrm{P}=0.004 ; \mathrm{P}<0.05$ ).

\section{Discussion}

Mid-clavicle fractures are the most common fractures of the clavicle. For the treatment of mid-clavicle fractures, 


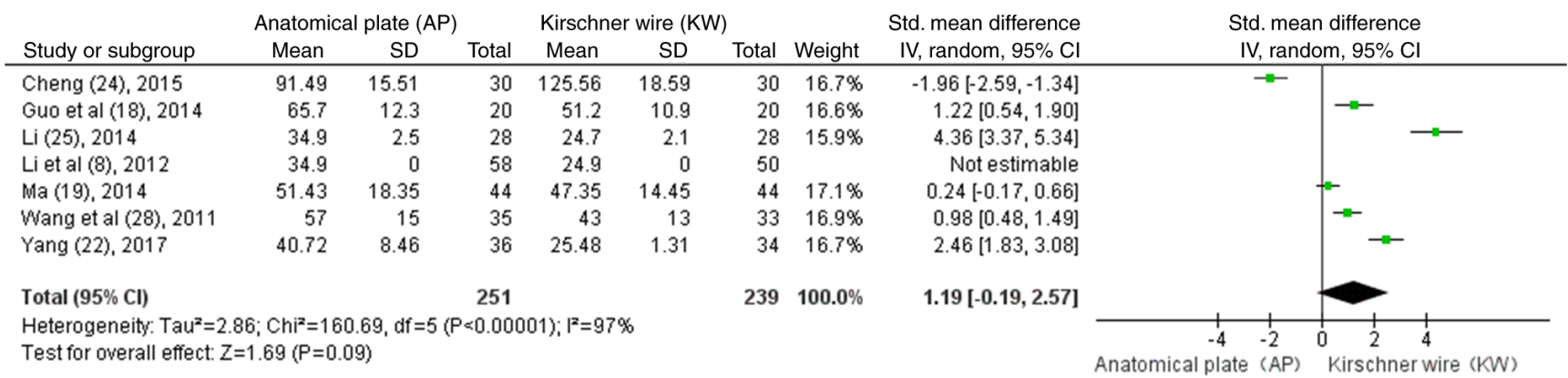

Figure 5. Comparison of duration of surgery between the AP and KW group. The diamond shapes represent the results of statistical analysis. The squares represent the weight of each study, and the horizontal lines represent the $95 \%$ confidence intervals for each study. The results revealed that the AP group had no significant advantage over the KW group in the duration of surgery for mid-clavicle fractures. AP, anatomic plate; KW, Kirschner wire.

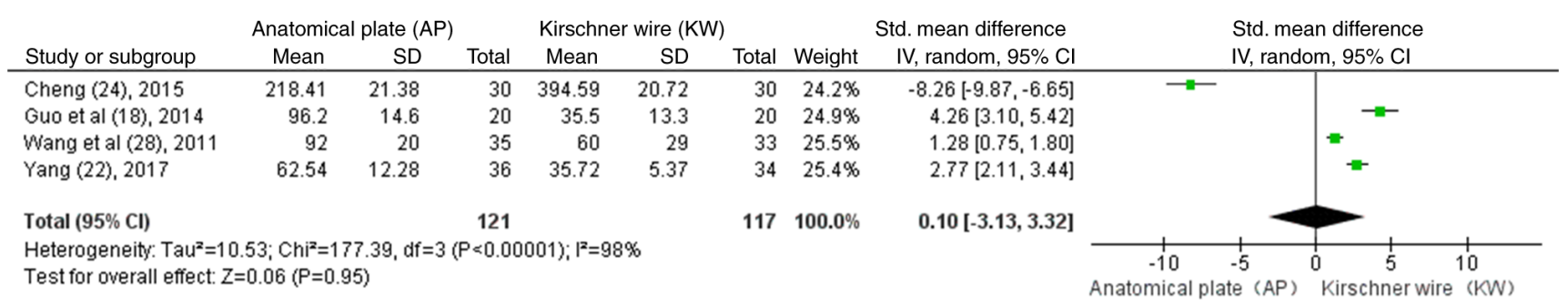

Figure 6. Comparison of blood loss between the AP and KW group. The diamond shapes represent the results of statistical analysis. The squares represent the weight of each study, and the horizontal lines represent the $95 \%$ confidence intervals for each study. The results revealed that surgical bleeding was not reduced in the AP group compared with the KW group. AP, anatomic plate; KW, Kirschner wire.

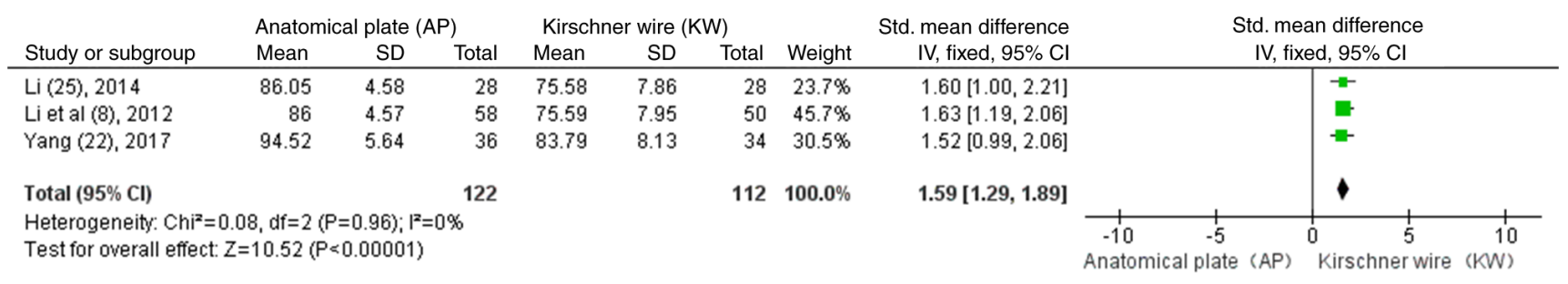

Figure 7. Comparison of constant function scores between the AP and KW group. The diamond shapes represent the results of statistical analysis. The squares represent the weight of each study, and the horizontal lines represent the $95 \%$ confidence intervals for each study. The results revealed that the AP group had a better recovery of function than the KW group. AP, anatomic plate; KW, Kirschner wire.

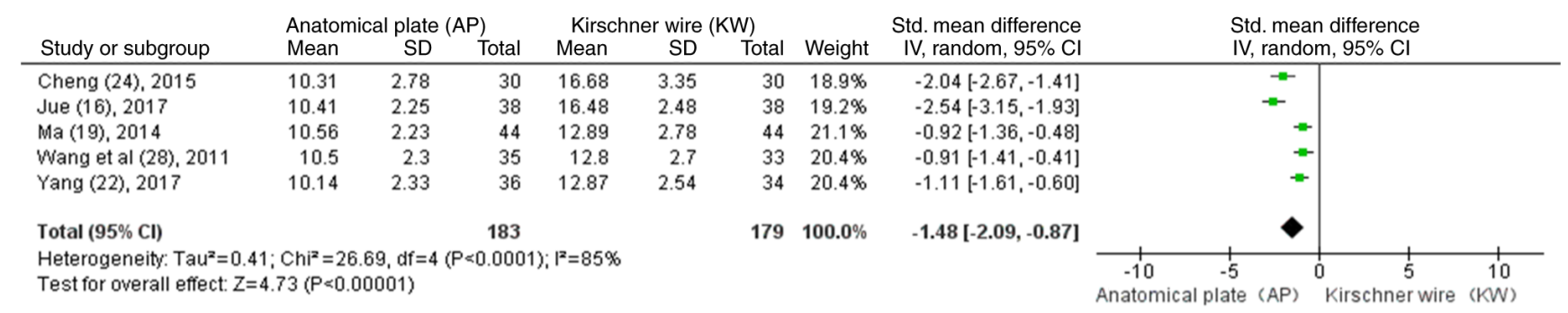

Figure 8. Comparison of fracture healing time between the AP and KW group. The diamond shapes represent the results of statistical analysis. The squares represent the weight of each study, and the horizontal lines represent the $95 \%$ confidence intervals for each study. The results revealed that the AP group had a shorter healing time and more rapid recovery than the KW group. AP, anatomic plate; KW, Kirschner wire.

particularly comminuted or unstable fractures, early surgical treatment is crucial for fracture healing and the avoidance of a second surgery. In the present study, through the analysis of the related studies of the treatment of mid-clavicle fractures with AP and KW fixation, it was found that the AP treatment of mid-clavicle fractures was associated with a better fracture healing, a shorter healing time, an improved post-operative function recovery, and the incidence of post-operative complications was significantly reduced compared with the KW group. 


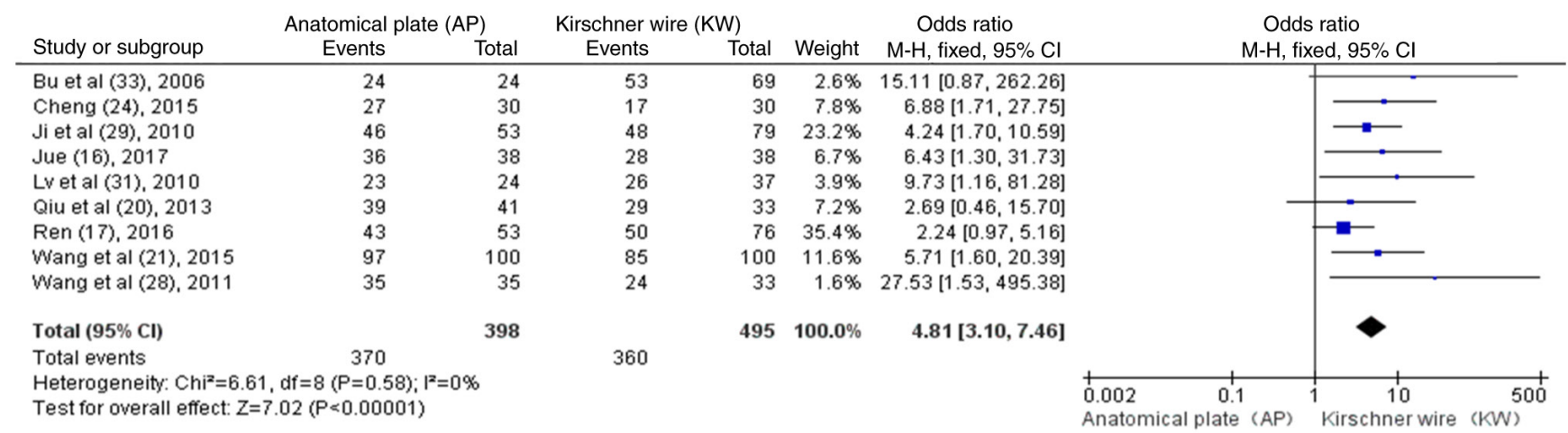

Figure 9. Comparison of post-operative curative effect between the AP and KW group. The diamond shapes represent the results of statistical analysis. The squares represent the weight of each study, and the horizontal lines represent the $95 \%$ confidence intervals for each study. The results revealed that the AP group had a better surgical prognosis than the KW group. AP, anatomic plate; KW, Kirschner wire.

\begin{tabular}{|c|c|c|c|c|c|c|c|c|c|}
\hline Study or subgroup & \multicolumn{2}{|c|}{ Anatomical plate (AP) } & \multicolumn{2}{|c|}{ Kirschner wire (KW) } & Weight & $\begin{array}{c}\text { Odds ratio } \\
\mathrm{M}-\mathrm{H} \text {, random, } 95 \% \mathrm{Cl}\end{array}$ & \multicolumn{2}{|c|}{$\begin{array}{l}\text { Odds ratio } \\
\mathrm{M}-\mathrm{H} \text {, random, } 95 \% \mathrm{Cl}\end{array}$} & \\
\hline Chen et al (23), 2015 & 1 & 30 & 3 & 10 & $7.7 \%$ & $0.08[0.01,0.89]$ & & & \\
\hline Guo et al (18), 2014 & 7 & 20 & 3 & 20 & $9.4 \%$ & $3.05[0.66,14.14]$ & & & \\
\hline Li et al (8), 2012 & 2 & 58 & 39 & 50 & $9.4 \%$ & $0.01[0.00,0.05]$ & & & \\
\hline Lv and Du (31), 2010 & 1 & 24 & 7 & 37 & $8.2 \%$ & $0.19[0.02,1.62]$ & & - & \\
\hline Ma (19), 2014 & 6 & 44 & 1 & 44 & $8.2 \%$ & $6.79[0.78,58.96]$ & & & \\
\hline $\operatorname{Ren}(17), 2016$ & 8 & 53 & 19 & 76 & $10.4 \%$ & $0.53[0.21,1.33]$ & & + & \\
\hline Tian (26), 2013 & 1 & 37 & 1 & 7 & $6.8 \%$ & $0.17[0.01,3.04]$ & & & \\
\hline Wang et al (28), 2011 & 0 & 35 & 7 & 33 & $6.8 \%$ & $0.05[0.00,0.91]$ & & & \\
\hline Yang et al (32), 2009 & 0 & 102 & 12 & 97 & $6.9 \%$ & $0.03[0.00,0.57]$ & & & \\
\hline Zhang (30), 2010 & 0 & $\begin{array}{r}128 \\
75\end{array}$ & 26 & 33 & $6.8 \%$ & $0.00[0.00,0.02]$ & & & \\
\hline Zhang et al (27), 2012 & 4 & 75 & 4 & 33 & $9.6 \%$ & $0.41[0.10,1.74]$ & & & \\
\hline Total $(95 \% \mathrm{Cl})$ & & 642 & & 474 & $100.0 \%$ & $0.16[0.05,0.55]$ & & & \\
\hline Total events & 33 & & 131 & & & & & & \\
\hline $\begin{array}{l}\text { Heterogeneity: } \operatorname{Tau}^{2}=3 \\
\text { Test for overall effect: } Z\end{array}$ & $\begin{array}{l}\mathrm{Chi}^{2}=58.28, \\
.91(\mathrm{P}=0.004)\end{array}$ & $P<0.00$ & $01) ;\left.\right|^{2}=81 \%$ & & & & $\begin{array}{lc}0.001 & 0.1 \\
\text { Anatomical plate } & (\mathrm{AP})\end{array}$ & $\begin{array}{l}10 \\
\text { Kirschner }\end{array}$ & $\begin{array}{l}1000 \\
(K W)\end{array}$ \\
\hline
\end{tabular}

Figure 10. Comparison of the post-operative complication rate between the AP and KW group. The diamond shapes represent the results of statistical analysis. The squares represent the weight of each study, and the horizontal lines represent the $95 \%$ confidence intervals for each study. The results revealed that the AP group had fewer surgical complications than the KW group. AP, anatomic plate; KW, Kirschner wire.

The credibility of a meta-analysis is dependent upon the quality of each study included. In the present meta-analysis, 20 Chinese studies were retrieved from the databases searched. Of the included studies, only eight mentioned the randomization of patients, and only two of these mentioned randomizations by number $(15,18)$. However, none of these randomized controlled studies mentioned that participants and treatments were assigned in a blinded manner. None of the studies was prospectively designed for sample size, and the end points of follow-up for each study case were randomized. Therefore, these deficiencies undermine the credibility of the study.

The KW is a commonly used means of internal fixation in clinical practice; however, it has no compression effect on the fracture end, and thus the displacement of the broken end and the occurrence of needle retreats are possible (8). The post-operative movement range of the $\mathrm{KW}$ is small, which often requires cervical wrist band fixation, severely affecting early movement. Although the present meta-analysis found that KW fixation had a smaller incision, the straightforward application of $\mathrm{KW}$ fixation was found to result in post-operative fracture end displacement, poor healing and a high rate of complications, which severely limit its clinical application. The AP has excellent adhesion and can be attached only with slight molding. It has a large post-operative mobility of the affected limbs and can be used for initial functional exercise and daily activities. However, excessive periosteum dissection can lead to delaying fracture union or bone non-union in order to achieve better adhesion.

The clavicle is the bone support structure connecting the scapula to the trunk. By attaching ligaments and muscles to the clavicle, the shoulder joint can be further stabilized. The state and time of clavicle healing severely affect the early functional movement of the shoulder joint. The present study found that compared with KW fixation, AP fixation has a wider force surface, stronger pressure effect, better resistance to bending stress and rotating force, and a higher biocompatibility. It not only reduces the slippage of internal fixation, but can also rapidly enter the functional training stage of the shoulder joint, which is in accordance with a previous study (29), further reducing the occurrence of periarthritis of the shoulder and joint stiffness.

The incidence of post-operative complications in the AP fixation group was significantly lower than that in the KW fixation group. Common post-operative complications include fixation loosening, Kirschner wire bending, fixation fracture, infection, needle withdrawal, malunion, and nonunion. 
However, in the included studies, the studies on postoperative complications were often limited in some aspects, which lead to a certain deviation in the study of postoperative complications in the two groups, and thus reduces the credibility of the meta-analysis.

By this meta-analysis, it was concluded that AP fixation is significantly superior to $\mathrm{KW}$ fixation in a number of aspects; however, there are some limitations that should be taken into account. First of all, the time of fracture, age, screw type, operative years, post-operative bandage fixation time, time to start functional exercise and other factors for each study should be considered; in addition, the consideration of post-operative aesthetics and economic issues should also be considered. Despite these limitations, the present study, to the best of our knowledge, is the first to provide a comprehensive clinical basis for comparing AP and $\mathrm{KW}$ fixation for the treatment of mid-clavicle fractures, providing a more valuable theoretical basis for clinical practice. The present study also had some limitations; it could not independently analyze the use of the two materials for common and complex clavicle fractures. In future studies, the authors aim to separately perform the comparison of the two surgical methods (AP and KW) for closed or open clavicle fractures, so as to further reduce the errors caused by the complexity of the surgical methods, affecting the credibility of the study.

\section{Acknowledgements}

Not applicable.

\section{Funding}

No funding was received.

\section{Availability of data and materials}

All data generated or analyzed during this study are included in this published article.

\section{Authors' contributions}

The title selection and design of the study were completed by DY and JZ. The retrieval, data extraction and analysis of the study were completed by all authors (DY, JZ and LW). The writing of the manuscript was completed by DY. The editing and revision of the manuscript was completed by JZ. All authors have read and approved the final manuscript.

\section{Ethics approval and consent to participate}

Not applicable.

\section{Patient consent for publication}

Not applicable.

\section{Competing interests}

The authors declare that they have no competing interests.

\section{References}

1. O'neill BJ, Hirpara KM, O'briain D, Mcgarr C and Kaar TK: Clavicle fractures: A comparison of five classification systems and their relationship to treatment outcomes. Int Orthop 35: 909-914, 2011.

2. Wang N, Zhang H, Yao Q, Wang Y, Dai S and Yang X: TGFBI promoter hypermethylation correlating with paclitaxel chemoresistance in ovarian cancer. J Exp Clin Cancer Res 31: 6, 2012.

3. d'heurrle A, Le T, Grawe B, Casstevens EC, Edgington J, Archdeacon MT and Wyrick J: Perioperative risks associated with the operative treatment of clavicle fractures. Injury 44: 1579-1581, 2013.

4. Strauss BJ, Carey TP, Seabrook JA and Lim R: Pediatric clavicular fractures: Assessment of fracture patterns and predictors of complicated outcome. J Emerg Med 43: 29-35, 2012.

5. Krishna R and Mongia AK: Outcome of surgical and conservative management of fractures of the middle-third of the clavicle. Indian J Orthop Surg 1: 87-92, 2015.

6. Canadian Orthopaedic Trauma Society: Nonoperative treatment compared with plate fixation of displaced midshaft clavicular fractures. A multicenter, randomized clinical trial. J Bone Joint Surg Am 89: 1-10, 2007.

7. Denard PJ, Koval KJ, Cantu RV and Weinstein JN: Management of midshaft clavicle fractures in adults. Am J Orthop (Belle Mead NJ) 34: 527-536, 2005.

8. Li YE, Tong Y, Ni QW, Tian NN and Wang CX: A comparative study of anatomical plate and Kirschner wire fixation in the treatment of middle clavicle fractures. Chin Med Herald 9: 162-163, 2012 (In Chinese).

9. Postacchjini F, Gumina S, De Santis P and Albo F: Epidemiology of clavicle fractures. J Shoulder Elbow Surg 11: 452-456, 2002.

10. Mckee MD, Pedersen EM, Jones C, Stephen DJ, Kreder HJ, Schemitsch EH, Wild LM and Potter J: Deficits following nonoperative treatment of displaced midshaft clavicular fractures. J Bone Joint Surg Am 88: 35-40, 2006.

11. Zlowodzki M, Zelle BA, Cole PA, Jeray K and McKee MD; Evidence-Based Orthopaedic Trauma Working Group: Treatment of acute midshaft clavicle fractures: Systematic review of 2144 fractures: On behalf of the evidence-based orthopaedic trauma working group. J Orthop Trauma 19: 504-507, 2005.

12. Stang A: Critical evaluation of the Newcastle-Ottawa scale for the assessment of the quality of nonrandomized studies in meta-analysis. Eur J Epidemiol 25: 603-605, 2010.

13. Higgins JP, Thompson SG, Deeks JJ and Altman DG: Measuring inconsistency in meta-analyses. BMJ 327: 557-560, 2003.

14. Lau J, Ioannidis JP and Schmid CH: Quantitative synthesis in systematic reviews. Ann Intern Med 127: 820-826, 1997.

15. Liu HF: The effect of anatomical plate internal fixation on the treatment of 70 cases of middle clavicle fractures and its influence on the shoulder joint function of patients. Chin Minkang Med 29: 49-50, 2017 (In Chinese).

16. Jue LL: Clinical analysis of anatomical locking plate in the treatment of middle clavicle fractures. Mod Health: 149, 2017. kns. cnki.net $/ \mathrm{kcms} /$ detail/detail.aspx? dbcode $=$ CJFD $\&$ dbname $=$ CJF DLASN2017\&filename $=$ YSXD201704133\&uniplatform $=$ NZKP T\&v=EFijtKCLk\%25mmd2FrRT069bZ7Hbmdx4ZcQUM6nPC Q5Ren\%25mmd2BMgSsVyghjsmWDhbCmMjCDpHn.

17. Ren XH: Comparison of treatment methods for middle-aged, young and old patients with fracture of the middle third of the clavicle. Prim Med Forum 20: 4216-4218, 2016 (In Chinese).

18. Guo WQ, Zeng ZH and Liu WJ: Analysis of curative effect of cluster Kirschner wire and anatomical plate in the treatment of middle clavicle fracture. Mod Hosp 14: 53-56, 2014 (In Chinese).

19. Ma ZY: Application of anatomical plate in emergency operation of comminution fracture of the middle clavicle. J Qiqihar Med Coll 35: 1601-1602, 2014 (In Chinese).

20. Qiu YF and Xiao DJ: Analysis of the curative effect of three internal fixation methods in the treatment of middle clavicle fractures. Chin Med Innovation 10: 107-109, 2013 (In Chinese).

21. Wang Q, Yang F and Cui B: Analysis of three methods of intramedullary fixation in the treatment of mid-clavicle fracture. Med Inf 24: 244-245, 2015 (In Chinese).

22. Yang XK: Comparison of the effects of internal fixation with anatomical plates and Kirschner wires on shoulder joint function and complications in patients with middle clavicle fractures. Chin Med Innovation 14: 59-62, 2017 (In Chinese). 
23. Chen JG, Liu B and Li ZD: Comparison of the curative effect of three surgical methods for clavicle fracture. Med Theory Pract 28: 3225-3226, 2015 (In Chinese).

24. Cheng J: Clinical research significance of anatomic locking plate in the treatment of mid-clavicle fracture. J Qiqihar Med Coll 36: 2559-2560, 2015 (In Chinese).

25. Li YW: The effect of S-shaped anatomical plate in the treatment of 28 cases of fractures of the middle and outer $1 / 3$ of the clavicle. Contemp Med Essays 12: 50, 2014 (In Chinese).

26. Tian WG: Analysis of surgical treatment of unstable middle clavicle fractures. Mod Diagn Treat 24: 2593-2594, 2013 (In Chinese).

27. Zhang WW, Yang JW, Hu XY, Li CJ, Wang B and Ren XH: Surgical treatment of unstable middle clavicle fractures. J Clin Orthop 15: 345-346, 2012 (In Chinese).

28. Wang T, Ye CQ and Chen GF: Comparison of the effect of internal fixation with anatomical steel plate and Kirschner wire in the treatment of middle clavicle fractures. Chin Med Clin 11: 1313-1314, 2011 (In Chinese).

29. Ji SJ, Ning SY, Qiao WS, Zhao Y, Qi X, Li SQ, Yang C and Yang JG: Comparison of treatment methods for middle-aged, young and old patients with fracture of the middle third of the clavicle. Chin J Gerontol 30: 2683-2684, 2010 (In Chinese).
30. Zhang NS: Analysis of curative effect of different internal fixation methods for middle clavicle fractures. Chin J Bone Joint Injury 25: 449-450, 2010 (In Chinese).

31. Lv PC and Du XY: Comparison of internal fixation with anatomical plate and kirschner wire in the treatment of comminution fracture of the middle clavicle. J Clin Orthop 13: 115, 2010 (In Chinese).

32. Yang SF, Chen J, PU ZK and Liu CC: Different internal fixation options for middle clavicle fractures. West Chin Med 24: 85-87, 2009 (In Chinese).

33. Bu BX, Zhang J, Shi FM Cao HY and Ma HS: Comparison of clinical efficacy of three internal fixation methods in the treatment of clavicle fracture. Chin J Orthop Trauma 2: 66-67, 2006. $\mathrm{kns} . \mathrm{cnki} . n e t / \mathrm{kcms} /$ detail $/$ detail. aspx $? \mathrm{dbcode}=\mathrm{CJFD} \& \mathrm{dbname}=$ CJFD2006\& filename $=$ ZGZG200602032\&uniplatform $=$ NZKPT $\& v=d i B e V w s p h 777 \% 25 \mathrm{mmd} 2 \mathrm{BbgnEjYCKt1} \% 25 \mathrm{mmd} 2 \mathrm{~B} 0$ unzld sE8AsylI4wbVExhJ9rqAxlj\%25mmd2FyAZnqifFEM.

c) (i) (9) This work is licensed under a Creative Common EY No No Attribution-NonCommercial-NoDerivatives 4.0 International (CC BY-NC-ND 4.0) License. 